\title{
Characterization of Fire Severity in the Moroccan Rif Using Landsat-8 and Sentinel-2 Satellite Images
}

\author{
Issam Eddine Zidane ${ }^{\mathrm{a}, *}$, Rachid Lhissou ${ }^{\mathrm{b}}$, Maryem Ismaili ${ }^{\mathrm{c}}$, Yassine Manyari ${ }^{\mathrm{c}}$, Abdelali Bouli $^{\mathrm{a}}$, \\ Mustapha Mabrouki ${ }^{\mathrm{d}}$ \\ ${ }^{a}$ Ecology and Sustainable development Laboratory, Sultan Moulay Slimane University, Faculty of Science and Technology, B.O.523, Beni \\ Mellal, Morocco \\ ${ }^{b}$ Environmental and Northern Remote Sensing Research Team, Institut National de la Recherche Scientifique, 490, de la Couronne, Québec \\ (Québec) G1K $9 A 9$ Canada. \\ ${ }^{c}$ Team of Remote Sensing and GIS Applied to Geosciences and Environment, Sultan Moulay Slimane University, Faculty of Science and \\ Technology, B.O.523, Beni Mellal, Morocco \\ ${ }^{d}$ Industrial Engineering Laboratory, Sultan Moulay Slimane University, Faculty of Science and Technology, B.O.523, Beni Mellal, Morocco \\ Corresponding author: *z.issam.13@gmail.com
}

\begin{abstract}
Forest ecosystems are exposed increasingly to a variety of human activities and accentuated by climate change. With its Mediterranean climate, Northern Morocco is very hot, which exposes forests to widespread fires. This work aims at the delineation of wildfires and the spectral characterization of burnt vegetation as well as the characterization of the fire severity in the North of Morocco by using Landsat-8, Sentinel-2 spectral data, and topographic data. The methods used include the derivation of wildfires spectral indices and the computation of topographic parameters (elevation, slope, exposure) from SRTM and PALSAR digital elevation models. Then, the Spectral Angle Mapper (SAM) classification was used to map forest fires' severity. Furthermore, we have compared the severity classes obtained from the SAM method applied to Landsat 8 and Sentinel 2 data, with different spectral indices specialized in detecting wildfires, on the one hand, and topographic data, on the other hand. Results showed that MIRBI and NBR indices allow a better characterization of burned areas than BAI index. For its part, SAM classification provides a fair characterization of the severity classes of burnt forests. It has also been shown that the MIRBI index and sun exposure are strongly correlated with severity classes. The obtained maps show the spatial heterogeneity of burns severity and how they interact with topography. These maps may help land resource managers and fire officials predict areas of potential fire hazards and study vegetation regrowth areas after fires.
\end{abstract}

Keywords - Sentinel-2 MSI; Landsat-8 OLI; forest fires mapping; NBR; BAI; spectral indices; Morocco.

\section{INTRODUCTION}

Forest fires are an essential disturbance factor in forest ecosystems, affecting the landscape, the natural vegetation cycle, ecosystem structure, and function [1], [2]. Also, changes in albedo and surface temperature after forest fires can significantly impact regional and global climate by changing surface energy flux patterns [3].

Fire damage estimation, such as burnt area and fire severity, is precious data for understanding how an ecosystem responds to fire disturbance [4], [5]. However, such field data are rarer, and their collection is generally costly in terms of time, financial, and human resources. The severity of a wildfire refers to her damage to the ecosystem, including tree mortality, and its impact on the quality of germination beds and underground parts of plants responsible for post-fire regeneration [6], [7]. Thus, weather conditions coupled with fuel properties will influence fire's behavior, affecting its severity; the latter is rarely evaluated, even from field data [1]. Remote sensing offers suitable alternatives to in situ measurements. Satellite remote sensing contribution to wildfire management is primarily concerned with identifying and monitoring burned areas and estimating fire damage [1], [8]-[10]. Therefore, it is useful in the analysis and planning of the rehabilitation of burned areas [11].

In this work, we aim to characterize the burned areas in the Moroccan Rif forest using satellite data from Landsat- 8 and Sentinel-2. The main objectives of this work are as follows: 
- Use of spectral indices and Spectral Angle Mapper (SAM) a supervised classification method for mapping burn severity.

- Study of the correlation between severity, spectral indices, and topographic parameters.

- Location, measurement, and mapping of fires that occurred in the Moroccan Rif in August 2016

- Spectral characterization of burned vegetation

\section{MATERIALS AND METHOD}

\section{A. Study Area and Data Used}

1) Geographical and Climatic Situation: The Moroccan Rif region is located in northern Morocco (Fig 1), characterized by a Mediterranean climate, with a scorching and dry summer influenced by both the Mediterranean Sea and the Atlantic Ocean.

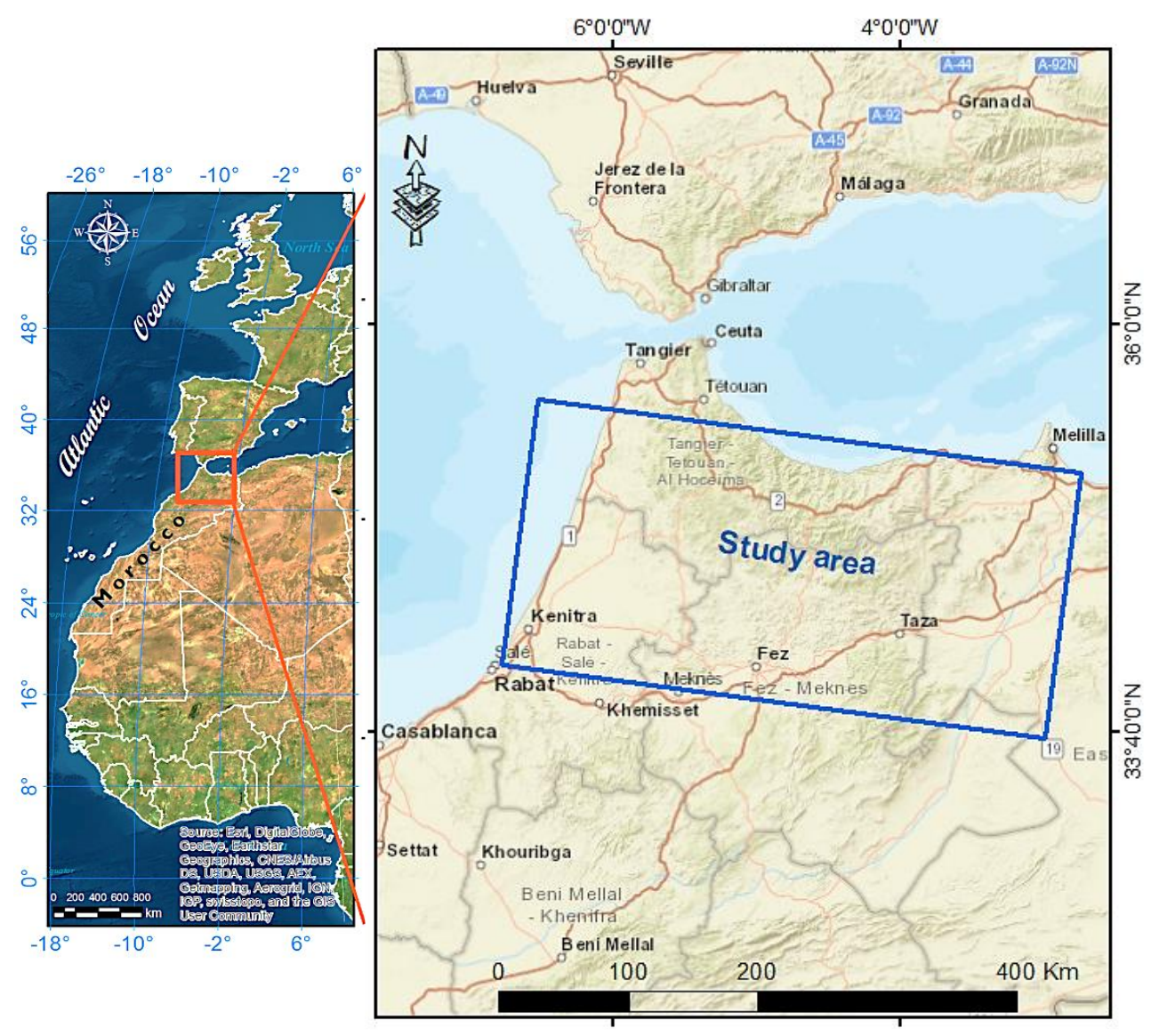

Fig. 1 Geographic location of the study area

This area was chosen as a study area because of its extensive forest cover and high exposure to forest fires. Indeed, $45 \%$ of fire departures are declared in this region, with $70 \%$ of the total area burned in Moroccan forests.

2) Forest Fires in Morocco: In Morocco, the forest domain is characterized by high biodiversity and high vulnerability to forest fires. Figure 2 shows the evolution of the number of fires from 1960 to 2015 , showing that fires' frequency is becoming more and more critical. The average burned area per year is 3000 ha and for an average fire starting of 280 ha, which gives $12 \mathrm{ha} /$ fire/year of the burnt surface. [12].Forests cover an area of 5, 814,000 hectares, with $63 \%$ of deciduous trees (holm oak, cork oak, acacia, and argan tree) and $20 \%$ of softwood (cedar, juniper, cypress, and pine). The other $17 \%$ occupied by lower formations (maternal and secondary species) often result from forest degradation. However, these forest formations are under pressure from various sources: difficult conditions for regeneration, climate change, unfavorable socio-economic environment, and a variable reforestation rate ( 3 to $40 \%$ ), making them even more vulnerable.

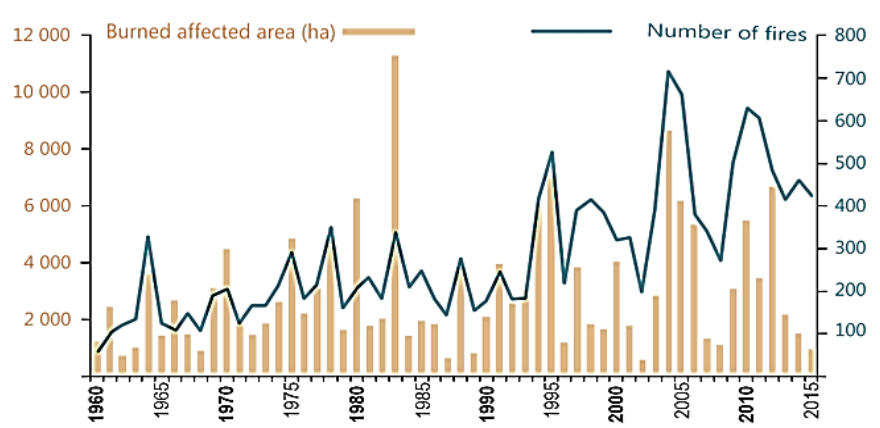

Fig. 2 Statistics on forest fires in Morocco [12]

3) Satellite Data: The spectral data used in this study are two images, one post-fire Landsat- 8 from the OLI (Operational Land Imager) sensor acquired on 10/08/2016 and the other post-fire Sentinel-2 image from the MSI (Multispectral Instrument) sensor acquired on 25/08/2016. Both sensors cover the visible, near-infrared (NIR) and Short- 
Wave Infrared (SWIR) spectrum. The comparison between the two sensors is shown in Fig. 3.

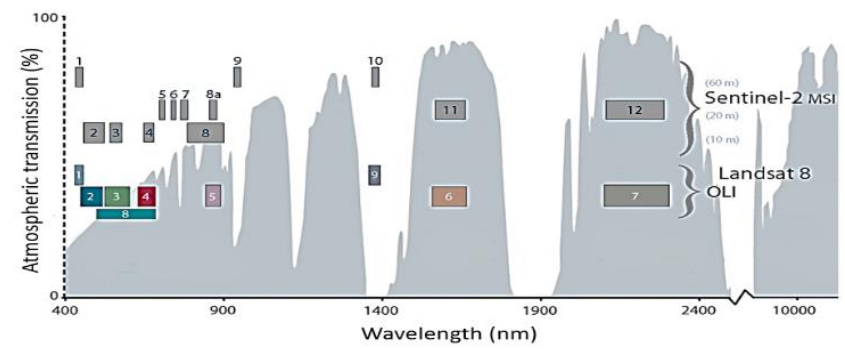

Fig. 3 Comparison between OLI Landsat- 8 and MSI sentinel-2 spectral bands
Shuttle Radar Topography Mission (SRTM) is an observation campaign to establish digital terrain models (DTM). It is the first high spatial resolution digital elevation model (DEM)so complete on Earth with 30 m [13], [14]. The Phased Array Type L-band Synthetic Aperture Radar (PALSAR) is an active microwave sensor using the L-band frequency to achieve cloud-free and day-and-night land observation. It provides higher spatial resolution DEM with $12.5 \mathrm{~m}$.

4) Fields Data: In total, five forest fires that occurred in August 2016 were considered in this study (Fig.4)

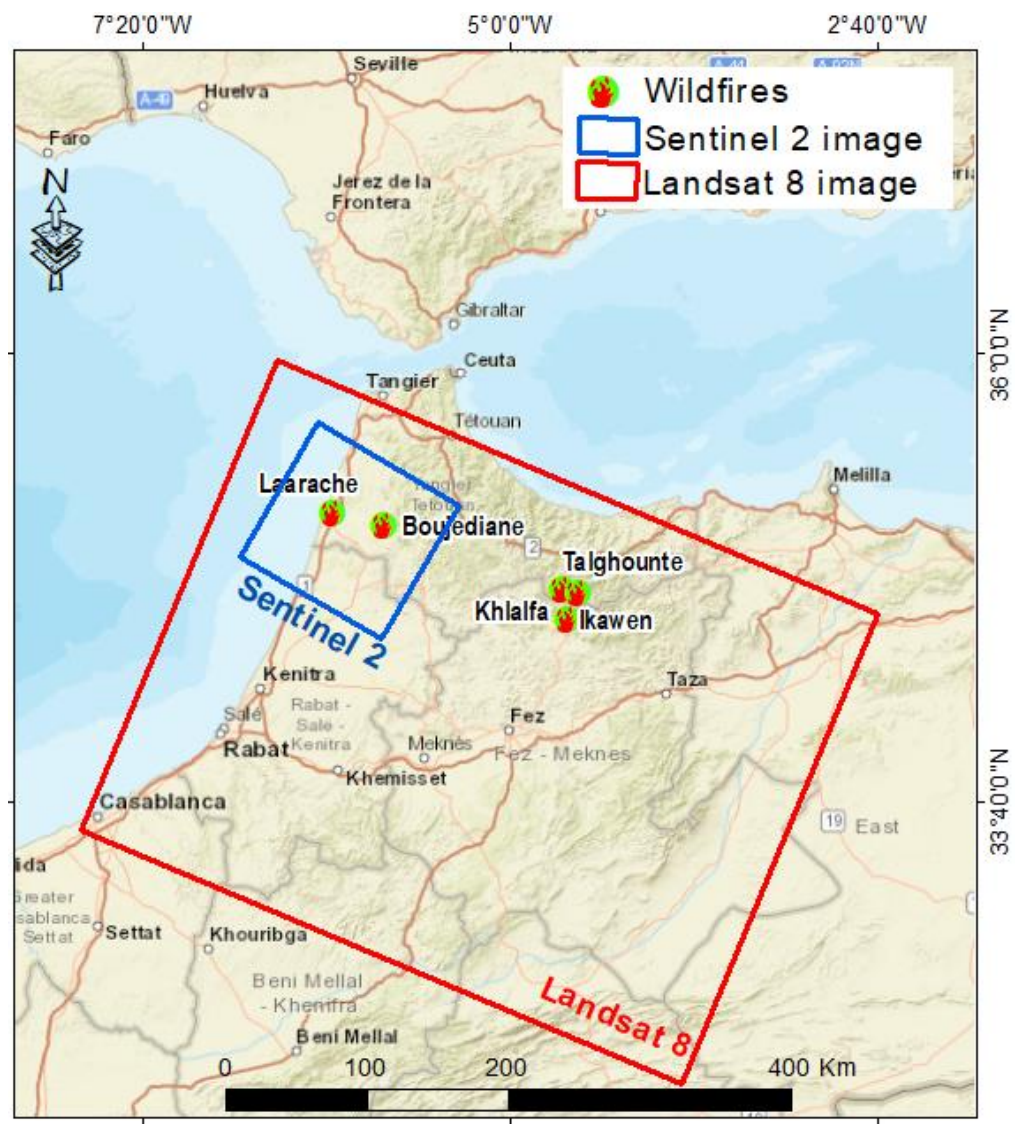

Fig. 4 Geographical location of the forest fires studied

\section{B. Methodology}

Figure 5 presents the methodology followed in this study and is composed of two main stages, i.e., preprocessing, treatment. Preprocessing, which consists of radiometric and atmospheric corrections of Landsat-8 OLI and Sentinel-2 MSI images. They are followed by transforming the coordinate systems for the different data used to provide the same coordinate system to be superposed. Treatments include some issues below:

- The calculation of forest fires' spectral indices, the visual interpretation of the colored composition (NIR/Red/Green/RGB).

- The calculation of topographic parameters (elevation, slope, exposure) from a DTM.

- The use of SAM classification to map the fires severity.
- The use of spectral indices for the characterization of wildfires.

- The study of the relationship between severity, spectral indices, and topographic parameters.

1) Pre-processing of Satellite Images: Atmospheric and radiometric corrections are essential steps in the processing of satellite images. They are used to subtract from the sensor's measured signal the target's signature, induced by atmospheric effects (absorption and scattering). First, the radiometric correction was performed by transforming the digital count into apparent reflectance. Second, atmospheric correction is the transformation of the apparent reflectance into the ground reflectance. 


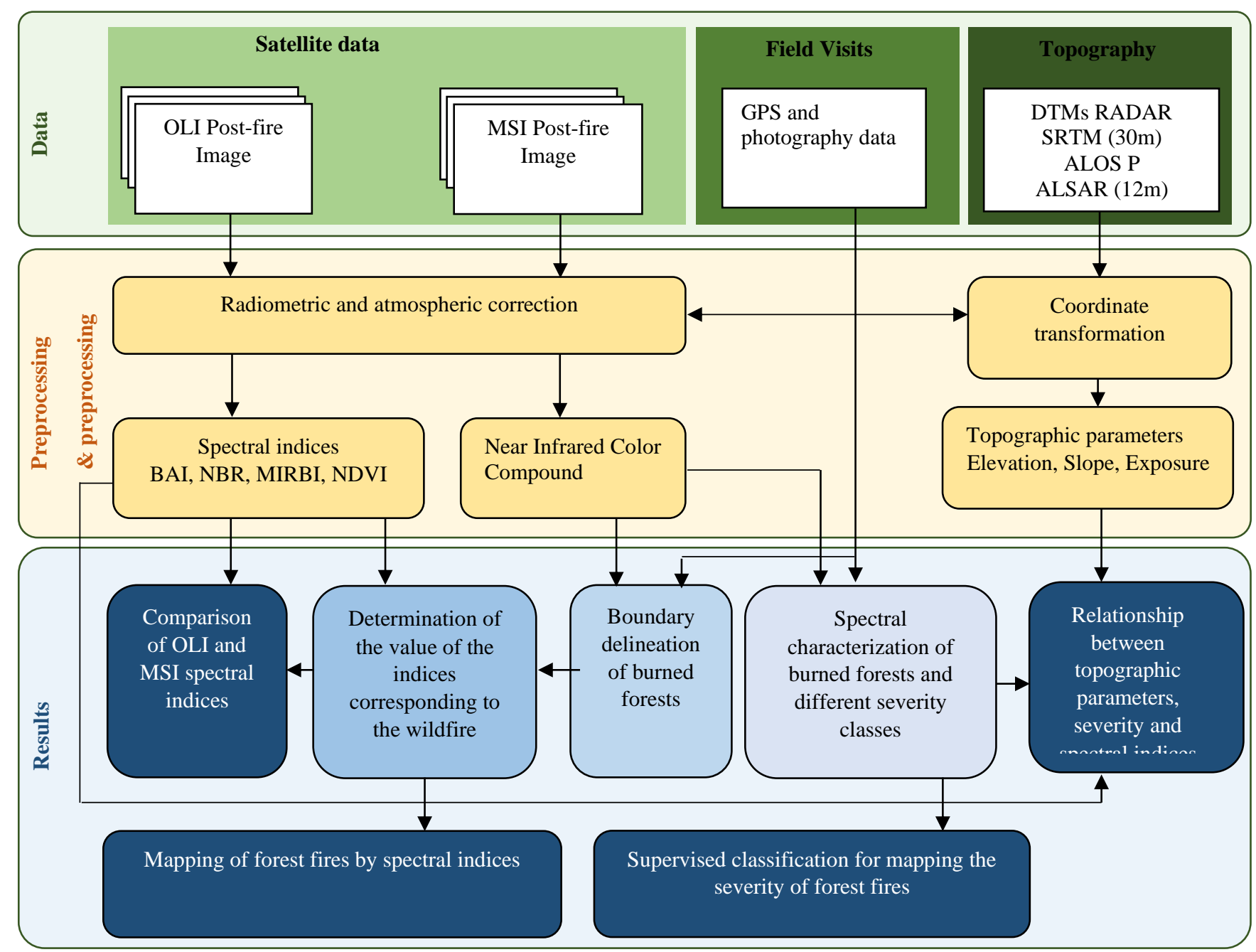

Fig. 5 Flowchart of the work methodology

2) Transforming the Digital Account into Radiance: Through the radiometric image calibration method which is a process of conversion from the digital count (DN) to reflectance values using standard equations. First, the Landsat OLI image is converted to radiance values according to equation 1 :

$$
\mathrm{L}(\lambda)=\mathrm{A}(\lambda) *(\mathrm{CN}(\lambda)-\mathrm{QCALMIN})+\mathrm{B}(\lambda)
$$

Where,

$\mathrm{L}(\lambda)$ : Apparent luminance (Radiance).

$\mathrm{CN}$ : Digital count for each pixel of the image.

$\Lambda$ : Wavelength.

$\mathrm{A}(\lambda)$ Gain $=(($ LMAX-LMIN $) /($ QCALMAX-QCALMIN $))$. LMAX and LMIN: Calibration constants.

QCALMAX and QCALMIN is the maximum and minimum values of the numerical account.

$\mathrm{B}(\lambda)$ Offset: LMIN.

3) Transformation of Apparent Luminance to Apparent Reflectance: After conversion to radiance, the image was converted to apparent reflectance. The relationship between apparent luminance and apparent reflectance is given by equation 2 :

$$
\rho^{*}(\lambda)=\frac{\pi \cdot D_{t}^{2} \cdot L^{*}(\lambda)}{E_{s}(\lambda) \cdot \mu_{s}}
$$

Where,

$\mathrm{E}_{\mathrm{s}}(\lambda)$ : Solar Irradiance $(\mathrm{W} / \mathrm{m} 2 . \mu \mathrm{m})$.

$\mathrm{D}_{\mathrm{t}}$ : Average Earth-Sun distance in astronomical units. $\mu_{\mathrm{s}}: \cos \left(\theta_{\mathrm{s}}\right), \theta_{\mathrm{s}}$ is the solar zenithal angle.

4) Atmospheric Correction: This correction aims to transform the radiance to the surface reflectance by eliminating the errors caused by the atmosphere. In this study, we have used Fast Line-of-sight Atmospheric Analysis of Spectral Hypercubes Fast Line-of-sight Atmospheric Analysis of Spectral Hypercubes (FLAASH) method to correct the Landsat- 8 OLI image, while we have used the Sent2Corr toolbox of the Sentinel-2 Toolbox software to correct the Sentinel-2 MSI image.

5) Spectral Characterization of Wildfire: Collecting the spectral signatures of burnt vegetation is quite simple using ENVI software. After the visual interpretation of several colored compositions, it seems that the composition NIR/Red/Green (RGB) gives a good view of the burned areas that appear as black areas. Based on the literature, these areas have low reflectance at the NIR level and high reflectance at the SWIR level, which is the opposite of healthy vegetation's reflectance. 
6) The computing of Spectral Indices for the Mapping of Wildfire: The principle of these operations is to perform, for each pixel, complicated mathematical operations involving the numerical values observed for this pixel in the different spectral bands. For example, one could calculate the sum of spectral values of a three-component image for each pixel, and the result is stored in a digital image with the same size as the original images. After calculating the spectral indices, we delimited burned surfaces, thus creating ROI (Region of Interest). The minimum, maximum, and average values of burnt vegetation indices were obtained automatically for each fire.

TABLE I

SPECTRAL INDICES USED IN THIS STUDY

\begin{tabular}{lcl}
\hline Spectral Indice & Equation & Source \\
\hline NDVI & $\frac{N I R-R}{N I R+R}$ & {$[15]$} \\
BAI & 1 & {$[16]$} \\
MIRBI & $(0.1-R)^{2}+(0.06-P I R)^{2}$ & \\
NBR & $10 S W I R 2-9.8 S W I R 1+2$ & {$[17]$} \\
& $\frac{N I R-S W I R}{N I R+S W I R}$ & {$[18]$} \\
\hline
\end{tabular}

7) SAM Supervised Classification of the Severity of Forest Fires: The SAM method was used to classify the severity of the fire. The latter was chosen because it showed its potential in the detection of burned areas [19], [20]. This classification is based on measuring the angular similarity between the spectrum of each pixel of the image and the reference spectra using a user-defined angle " $\alpha$ ". The reference spectra can be measured directly in the field using a spectroradiometer or extracted from the image. Assigning a pixel of the image to a given class is based on the value of $\alpha$ angle. The pixel will be assigned to its most similar spectral class. Noting that reducing $\alpha$ value, the expected similarity is more significant than [21]. In our case, the reference spectral signatures used to run the SAM were extracted from the image. They represent five fire severity classes according to the literature and a class of healthy vegetation.
8) Relationship between Severity, Spectral Indices and Topographic Parameters: Understanding the factors controlling fire severity requires considering the scale of how these factors work. This approach highlights the relationship between forest fire severity and topographic parameters. To this end, the ArcGIS software was used to calculate topography parameters and extract statistical data from severity classes.

\section{RESULTS AND DISCUSSION}

\section{A. Spectral Characterization of Burned Vegetation}

In the visible spectrum, the reflectance of burned areas with intense fires, where vegetation has been strongly affected, decreases because of leaf chlorophyll loss. However, the reflectance of shade, water, wetlands, and dense coniferous forests is similar and can lead to confusion [22], [23].

The NIR is known to be strongly reflected by chlorophyllA, which makes it easy to distinguish between healthy and recently burned vegetation. The reflectance of burned areas in the NIR is much lower than that of healthy areas. This difference will allow for the discrimination of burn severity degrees.

In the SWIR, the reflectance increases when the plants' humidity decreases; the increase in reflectance in the SWIR is more significant than in the visible spectrum. Finally, the reflectance of burned areas in SWIR is lower than that of unburned areas (bare soil, rock outcrops, or urban areas) and higher than the reflectance of healthy vegetation and water [22], [23]. Fig 6 and 7 show the spectral signatures from the Landsat-8 OLI and Sentinel -2 MSI images. In overall, the increase in reflectance over burnt surfaces is higher in the SWIR than in the visible and proportional to the burn severity and thus considered the NIR/SWIR bispectrality space more appropriate for burnt area discrimination and severity mapping than the classical visible/NIR space used often in remote sensing of vegetation.

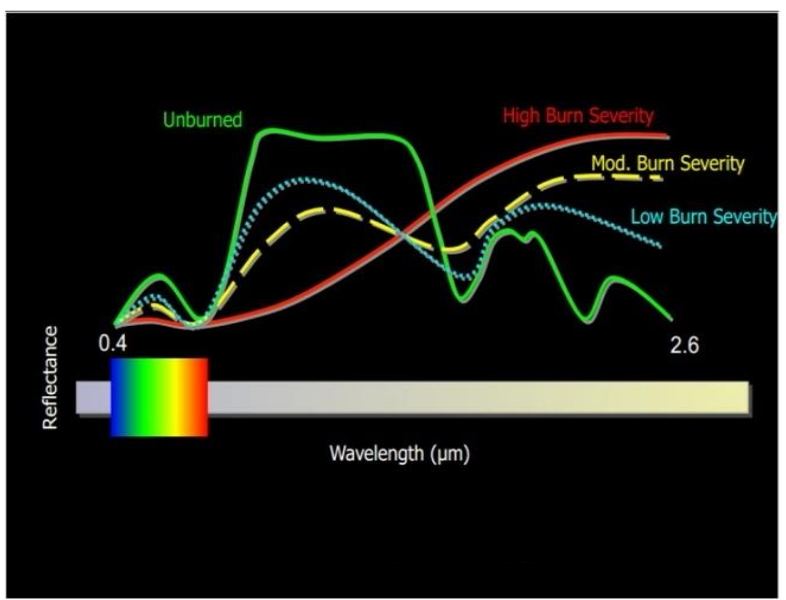

Spectral signature of severity classes in literature

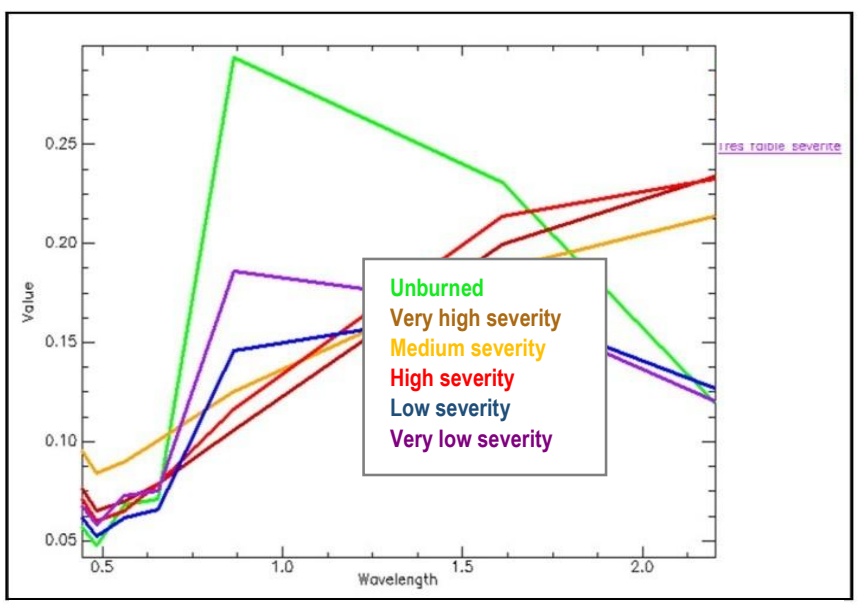

Spectral signature of severity classes in our case with OLI

Fig. 6 Spectral signatures of severity classes (left: signatures from the literature[24], right: signatures extracted from Landsat-8 OLI image) 


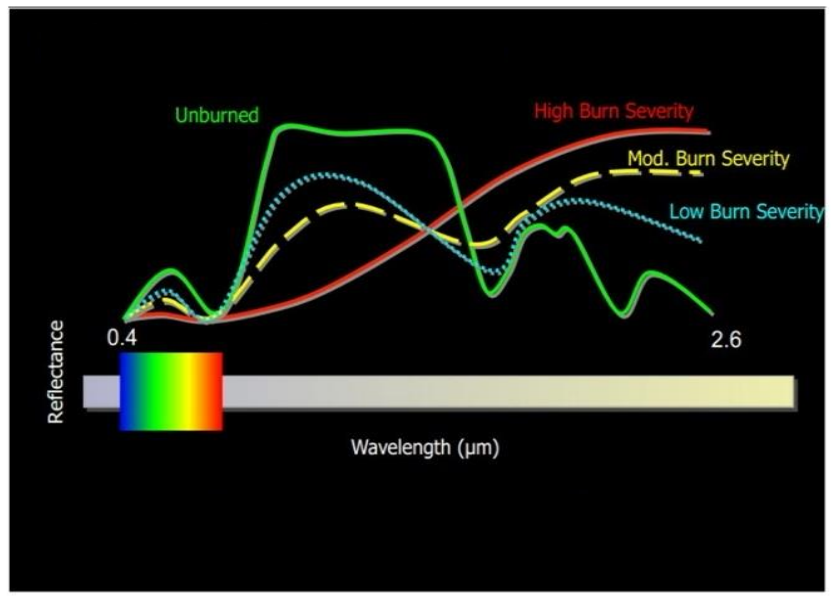

Spectral signature of severity classes in literature

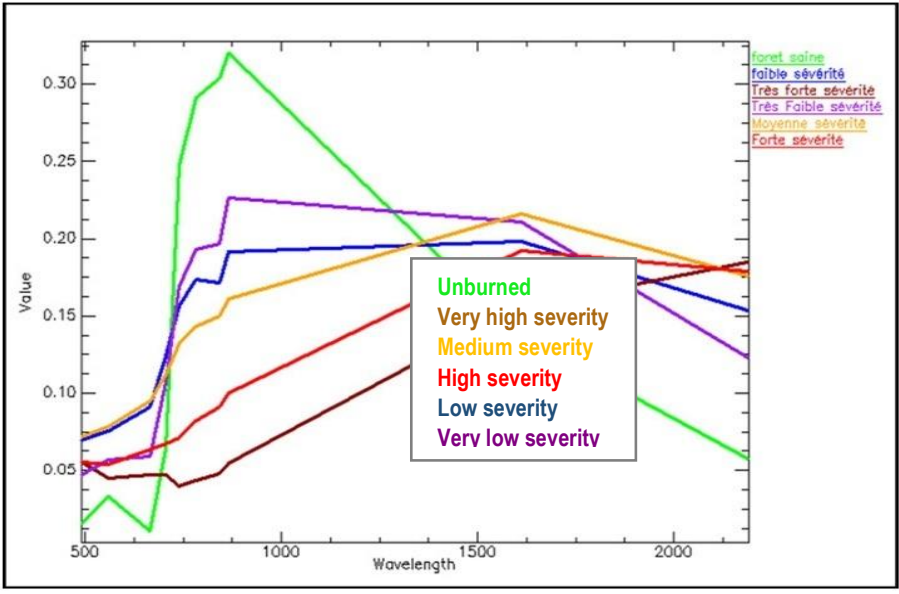

Spectral signature of severity classes in our case with Sentinel 2

Fig. 7 Spectral signatures of severity classes (left: signatures from the literature[24], right: signatures extracted from our Sentinel-2 MSI image)

\section{B. Characterization of Forest Fires using Spectral Indices}

1) Comparison of Forest Fire Spectral and Vegetation Index NDVI: The values of the BAI, MIRBI, NBR, and NDVI indices give different values in healthy and burned areas (Tables 2-3). The NDVI values are very low but not negative, which shows that the burned areas were rich in vegetation. The other fire indices have maximum values in burned areas, and they take minimum values in areas where there is healthy vegetation except the NBR, which shows the opposite.

Making the visual interpretation of the spectral indices in Figures 8-10, we note that MIRBI and NBR give the best results compared to the other indices, while NBR-S2 is better than NBR-OLI. This result can be explained by the fact that the NIR/SWIR bispectrality space has a stronger discriminant ability for burned surfaces than the classical NIR/visible space since MIRBI and NBR use NIR and SWIR, multispectral bands, while BAI uses only NIR band.

This finding corroborates well with the results of Pereira et al. [23] who demonstrates that the SWIR/NIR has, in general, the higher capability to identify burns than the visible range, and the SWIR spectral region is also much less sensitive to atmospheric disturbances. The outperformance of Sentinel 2 NBR may be due to the high spatial and spectral resolution of this sensor.

The BAI does not discriminate well with OLI and gives an awful result with Sentinel-2; this is due to the coefficients used in the BAI equation, which is only adapted to the Landsat-8 data.

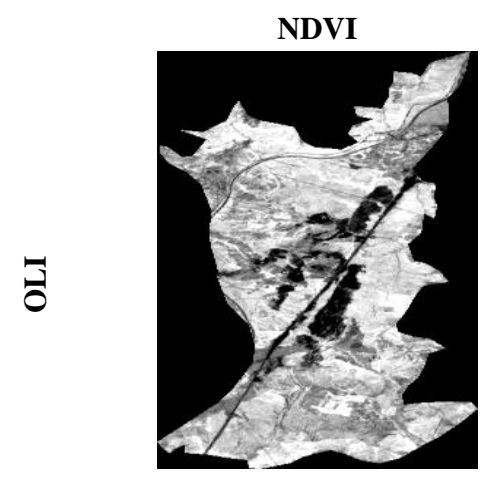

BAI

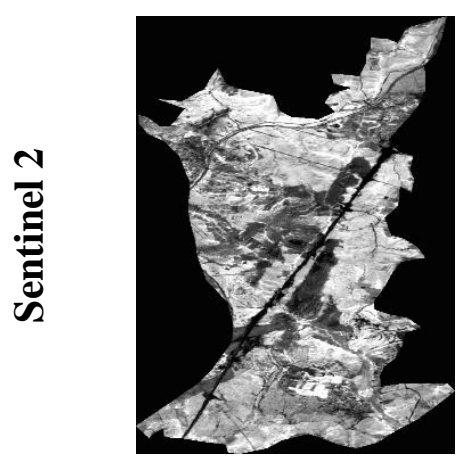

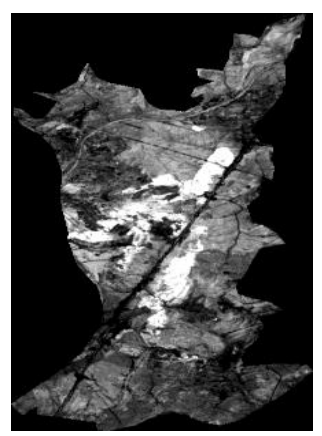

NBR
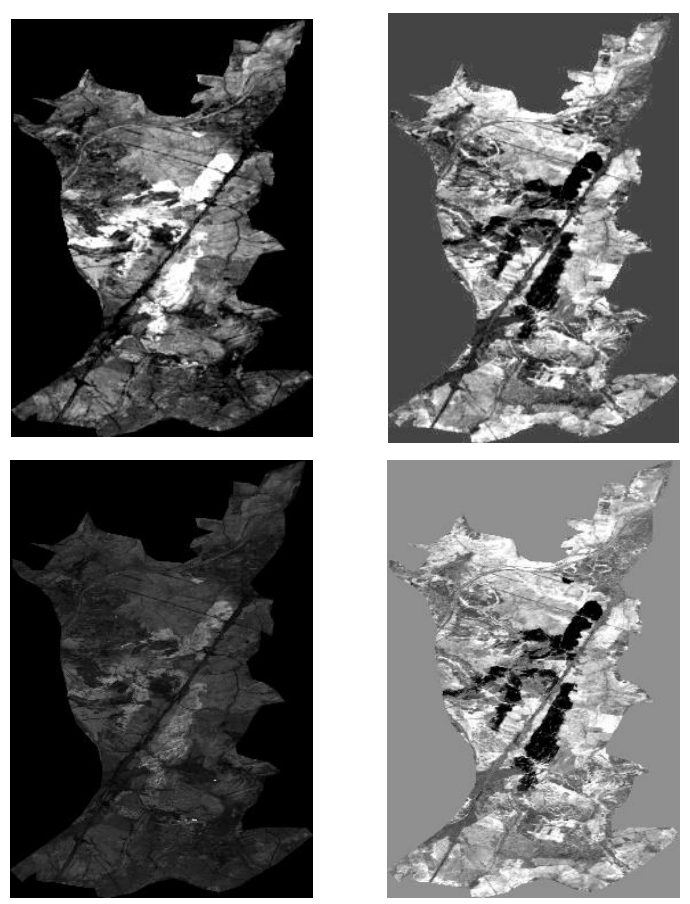

MIRBI

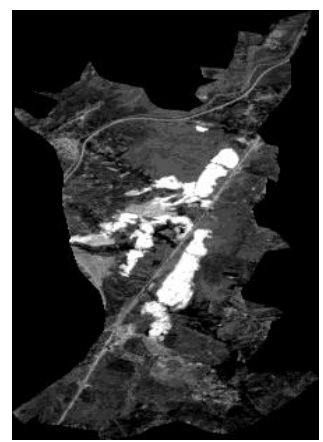

Fig 8 Maps of spectral indices (NDVI, BAI, NBR, MIRBI) for Laarach Forest from Landsat-8 and Sentinel-2 data 

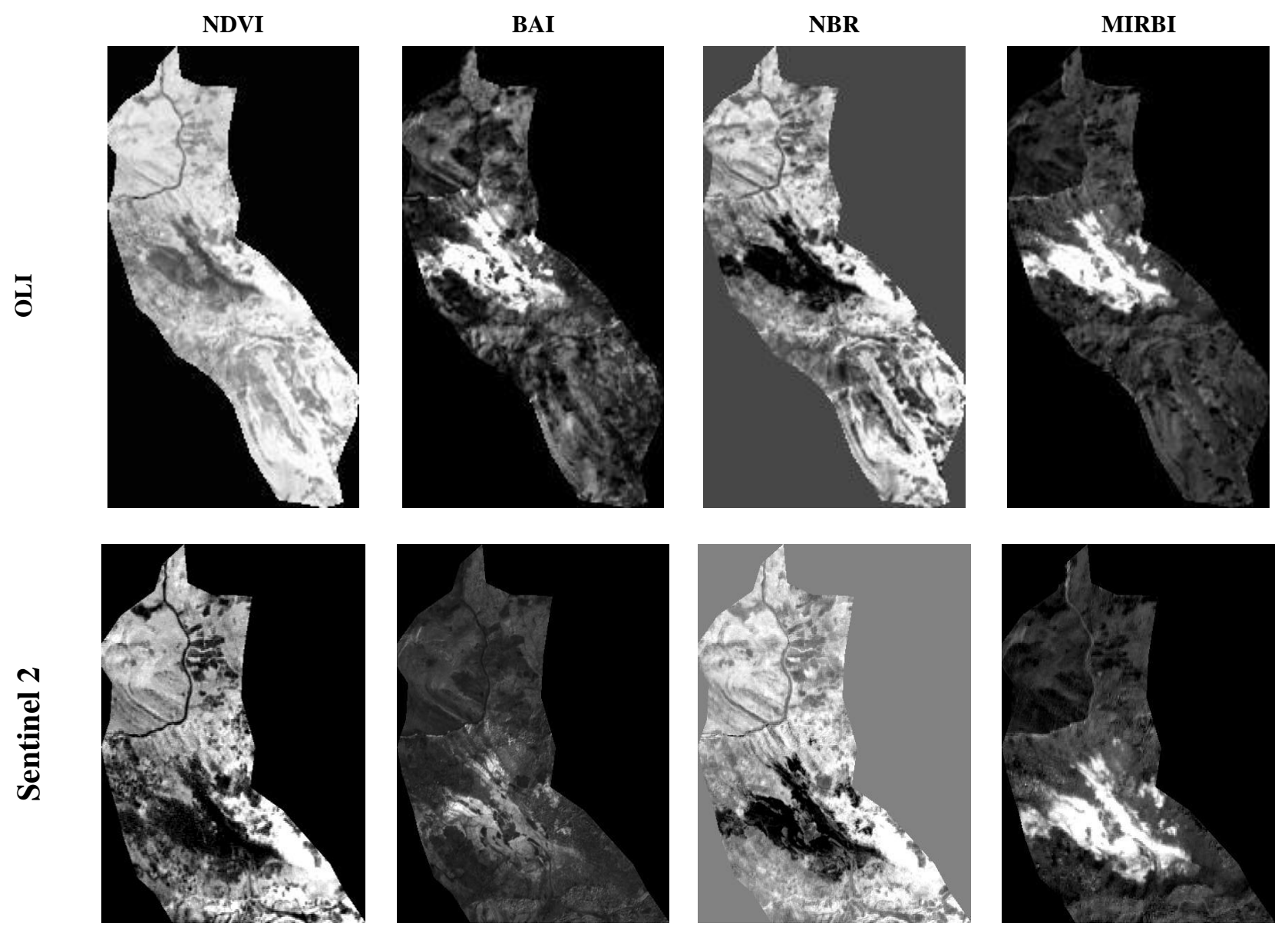

Fig. 9 Maps of spectral indices (NDVI, BAI, NBR, MIRBI) for Boujedyane Forest from Landsat-8 and Sentinel-2 data
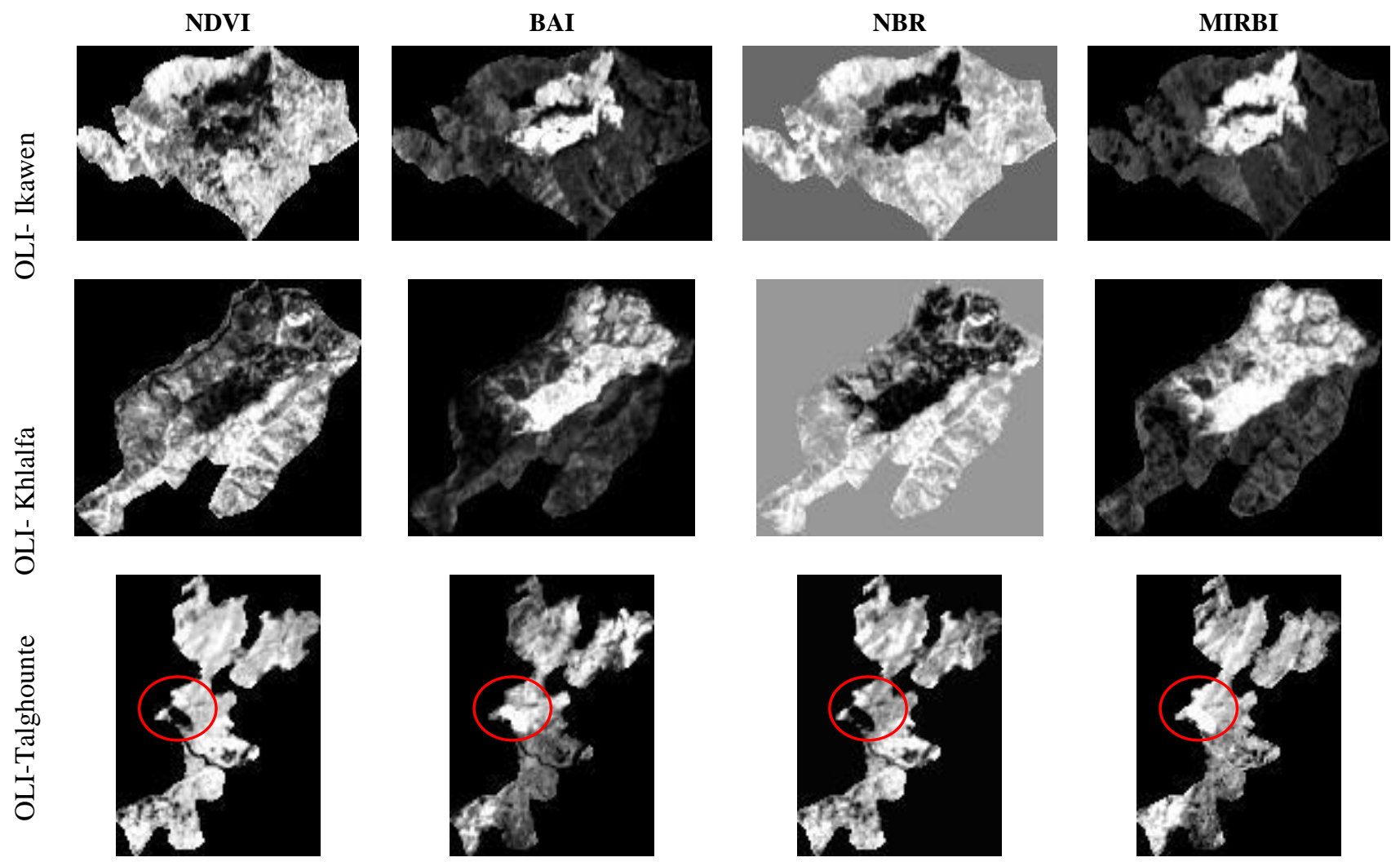

Fig. 9 Spectral index maps (NDVI, BAI, NBR, MIRBI) for Ikawen, Khlalfa and Talghounte forests from Landsat-8 
2) Determination of Index Values for Burnt Vegetation: To map burned forests, it is essential to extract the values from the corresponding indices. In this case, we used the automatic method of extracting the statistics using ROI Stats tool implemented in the Envi software. Tables II and III show the ranges of BAI, NBR, and MIRBI values for mapping burnt vegetation. These values are different from those of healthy vegetation, noting that MIRBI and NBR give the best separation compared to BAI, which may be related to the fact that both indices are based on the SWIR better characterizing burnt forests as discussed above.

TABLE II

SPECTRAL INDEX VALUES CORRESPONDING TO THE HEALTHY AND BURNED FOREST FOR LANDSAT-8 OLI

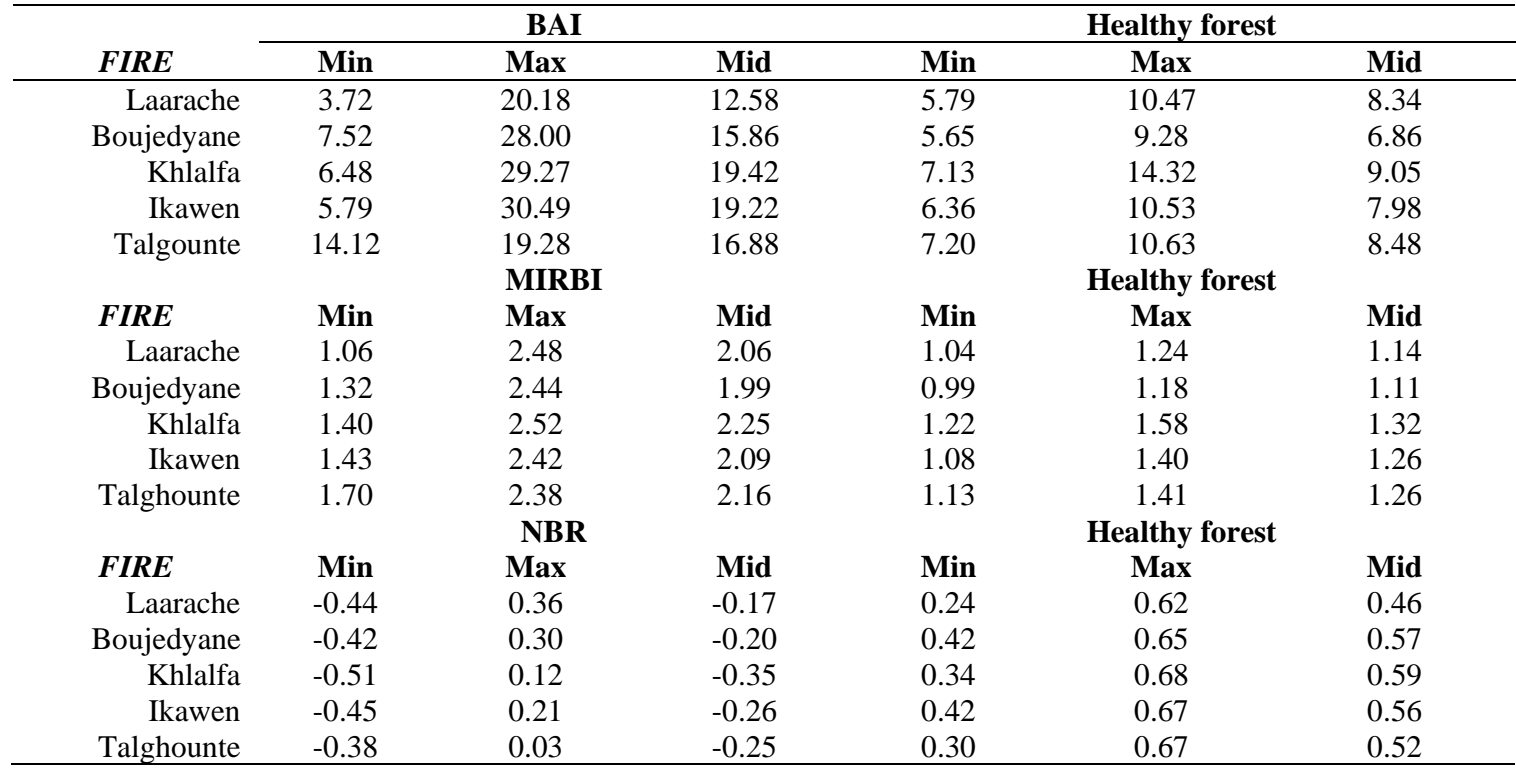

TABLE III

SPECTRAL IndEX VALUES CORRESPONDING to THE HEALTHY AND BURNED FOREST FOR SENTINEL-2 MSI

\begin{tabular}{|c|c|c|c|c|c|c|}
\hline \multirow[b]{2}{*}{ FIRE } & \multicolumn{3}{|c|}{ BAI } & \multicolumn{3}{|c|}{ Healthy forest } \\
\hline & Min & Max & Mid & Min & Max & Mid \\
\hline Laarach & 5.02 & 37.53 & 21.58 & 7.02 & 12.08 & 9.32 \\
\hline \multirow[t]{2}{*}{ Boujedyane } & 3.10 & 34.25 & 16.77 & 5.97 & 11.75 & 8.21 \\
\hline & & MIRBI & & \multicolumn{3}{|c|}{ Healthy forest } \\
\hline FIRE & Min & Max & Mid & Min & Max & Mid \\
\hline Laarach & 2.02 & 2.07 & 2.03 & 2.03 & 2.04 & 2.03 \\
\hline Boujedyane & & NBR & & \multicolumn{3}{|c|}{ Healthy forest } \\
\hline FIRE & Min & Max & Mid & Min & $\operatorname{Max}$ & Mid \\
\hline Laarach & -0.65 & 0.41 & -0.28 & 0.21 & 0.57 & 0.37 \\
\hline Boujedyane & -0.68 & 0.42 & -0.41 & 0.09 & 0.65 & 0.56 \\
\hline
\end{tabular}

\section{SAM Classification Severity Maps}

We use the extracted spectral signatures in the SAM classification. The maps resulted are shown in Fig 11 and 12. They show that the healthy forest in the OLI and Sentinel-2 images are well mapped as well as the other severity classes. However, there is a slight confusion between healthy forests and the very weak and weak class reported by different studies [25]-[27]. In general, the SAM classification has given satisfactory results in mapping the severity of forest fires. The latter showed small differences in the middle classes, high and very high severity classes. This difference may be due to the spectral difference between the two sensors. We have also used the same similarity angles in the SAM classification, and perhaps using a different angle for each sensor can reduce the difference in the resulting maps. These maps may help land resource managers assess the magnitude of environmental change caused by fire, the resulting level of costs in socioeconomic terms, and manage areas of vegetation regrowth after fires. 

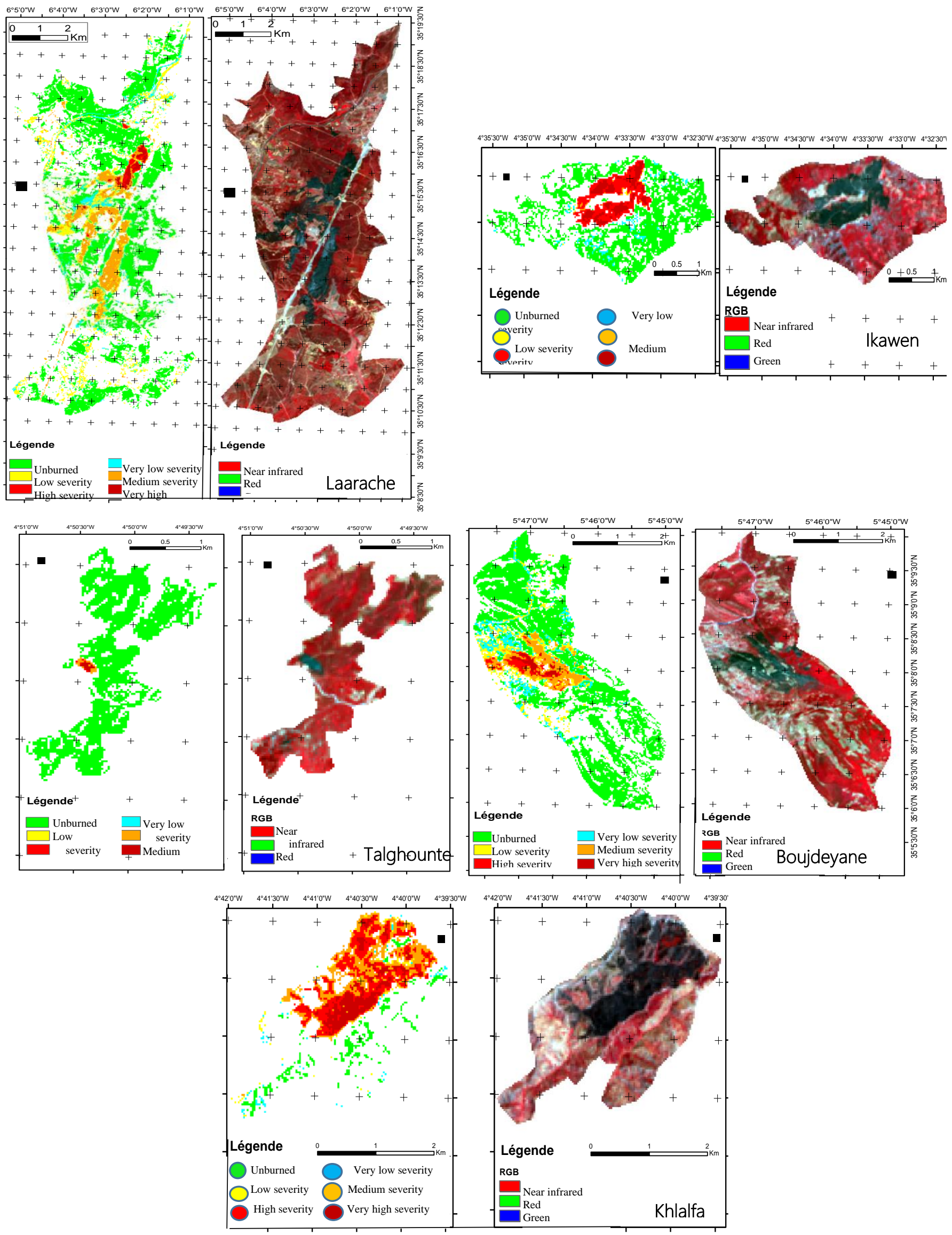

Fig. 10 SAM Classification Severity Maps - Landsat-8 OLI 


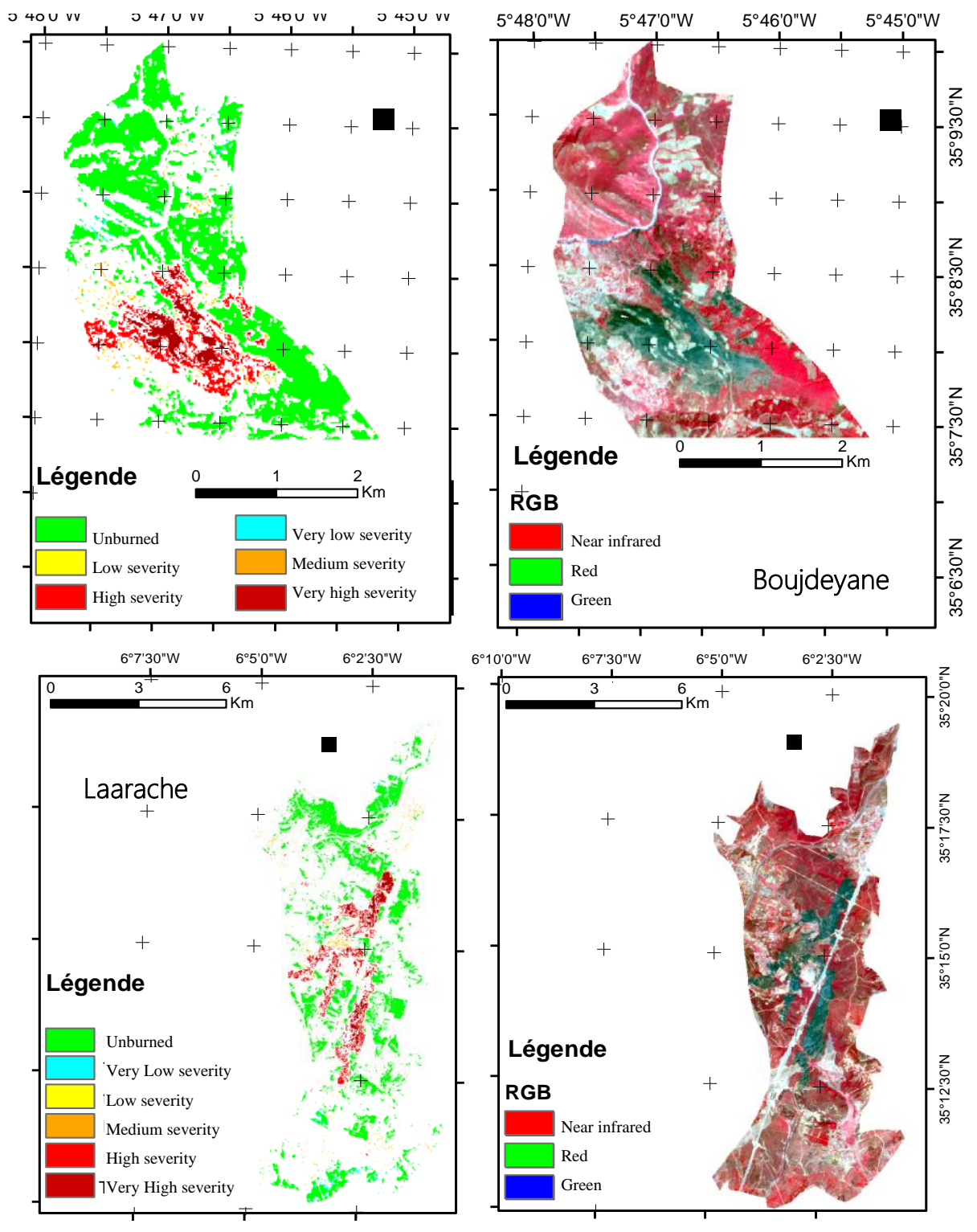

Fig. 11 SAM Classification Severity Maps - Sentinel 2

D. Relationship between Severity, Spectral Indices, and Topographic Parameters

Figures 14 and 15 show a strong relationship between severity classes, spectral indices, and topographic parameters. We notice that MIRBI and NBR are the most correlated spectral indices with the severity classes noting that MIRBI was slightly more successful. Across the five wildfires studied, the determination coefficient $\mathrm{R}^{2}$ of MIRBI varies from 0.96 to 0.99 and 0.44 to 0.49 for Landsat8 and Sentinel2, respectively (Figure 13).

As for the topographical parameters, we note that the heavily burned forests are exposed to the west, northwest, and southwest, which corresponds to the strong afternoon illumination (Figure 14). The slope also showed a negative correlation to severity, but not in all the studied forests. Intense fires are located towards the slight slopes. Human factors can explain this case, as urban areas and human activities are more intense on shallow slopes. Concerning elevation, it showed a low correlation in forests with a low elevation of less than $900 \mathrm{~m}$ (Laarache, Khlalfa, and Boujedyane), whereas it is positively correlated in forests with high elevation. The comparison of burn severity and topographic features reveals the complex phenomena behind a burned area. Studying the severity provides alternative tools to prevent future forest fires in the function of the topography, vegetation, or environmental factors. 

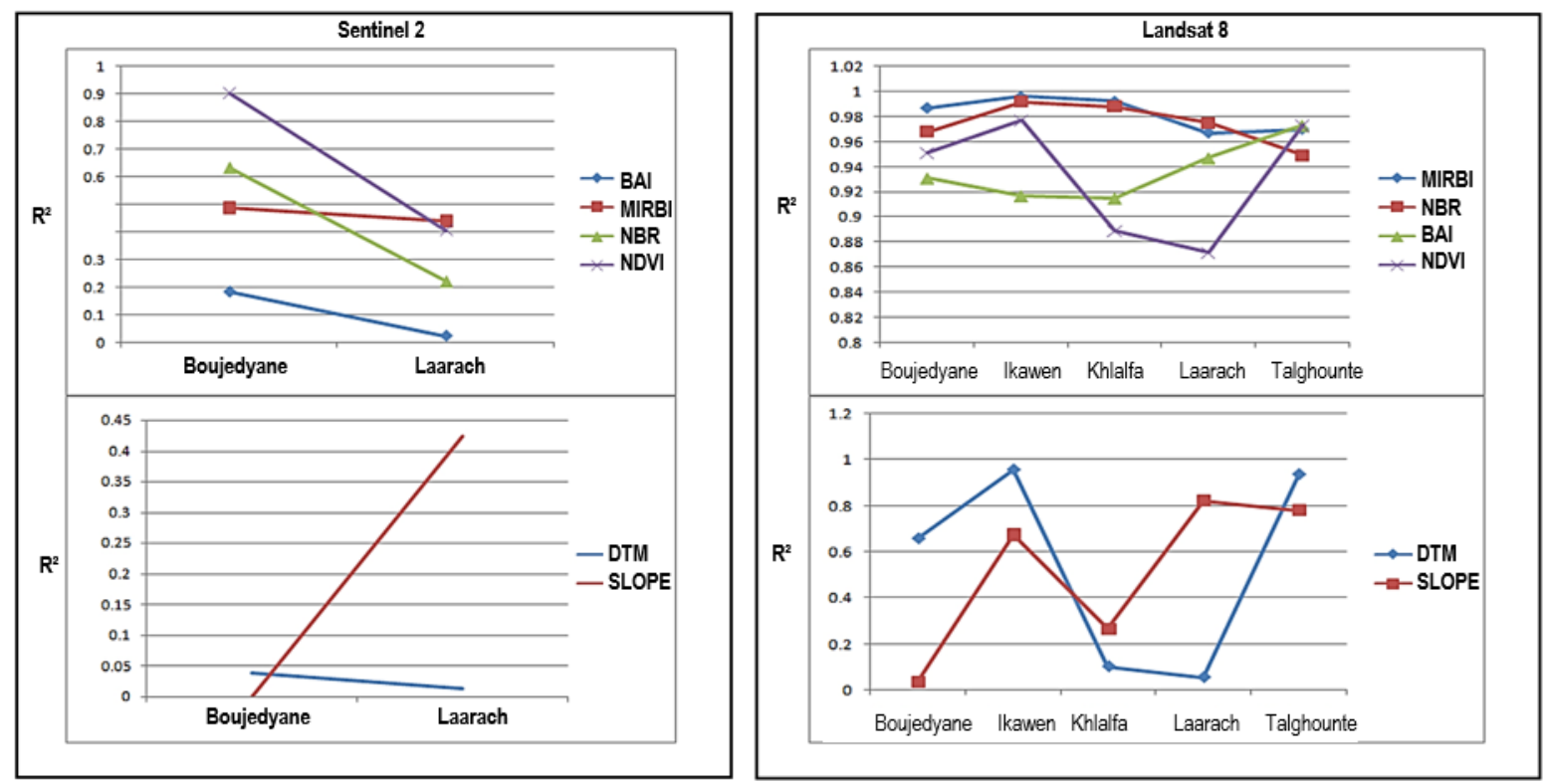

Fig. 12 Summary of $\mathrm{R}^{2}$ correlation between severity class correlation and spectral indices, elevation and slope
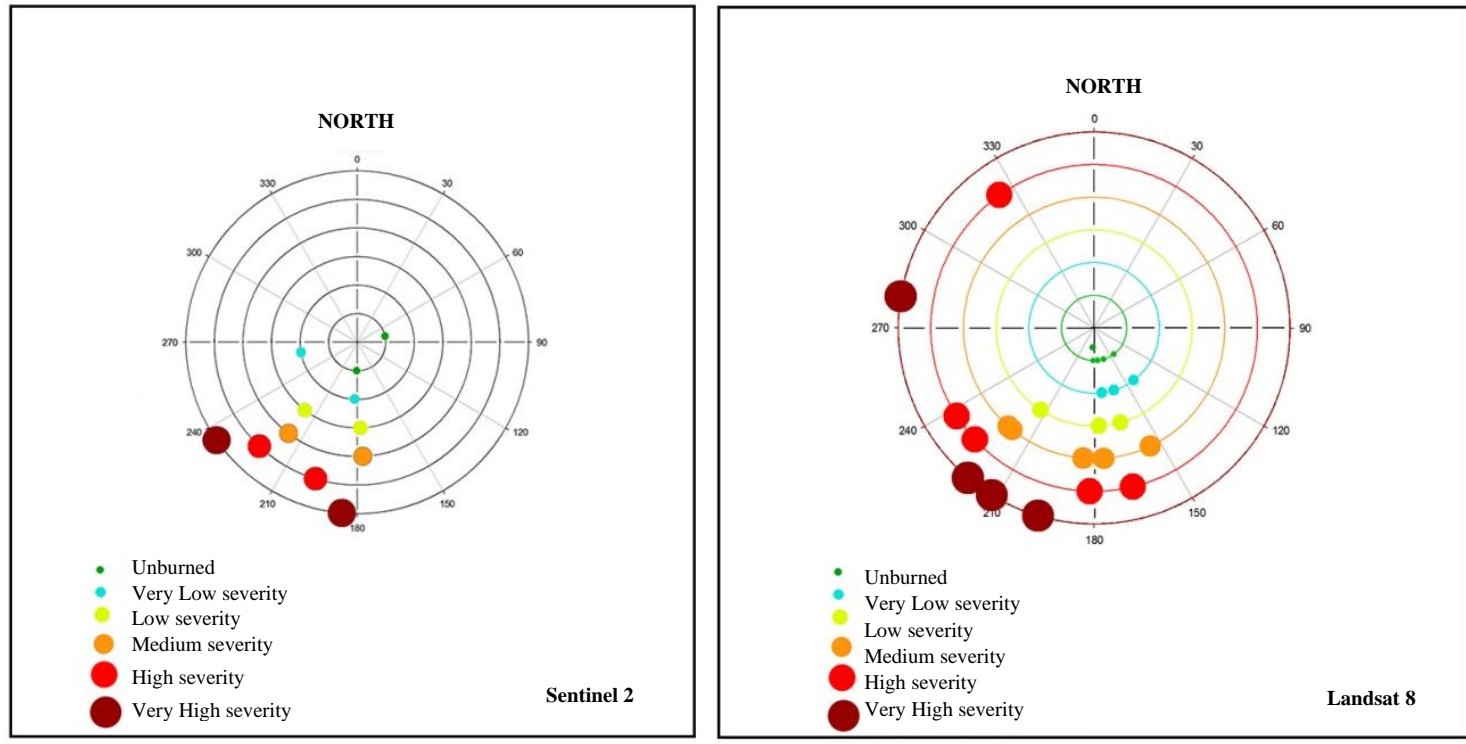

Fig. 13 Correlation of severity classes with sun exposure

\section{CONCLUSION}

This work focused on studying forest fires in the Rif of Morocco using Landsat-8, Sentinel-2 spectral data, and topographic data. First, a spectral characterization was carried out, which showed that deterioration of the inner leaf structure, decrease in chlorophyll content, and moisture in burned vegetation leads to an increase in spectral response in the wavelength of the SWIR and decrease in NIR.

In a second step, spectral index methods and the Spectral Angle Mapper method were used. The results of this work can be classified as follows:

- The NIR/SWIR bispectrality space is appropriate for burnt area discrimination and severity.

- The ranges of BAI, NBR, and MIRBI values for mapping burnt vegetation have been identified,

- MIRBI and NBR give the best cards by noting that NBR$\mathrm{S} 2$ is better than NBR-OLI,
- SAM classification has given satisfactory results in fire severity mapping and requires field validation to quantify classification errors,

- The two indices MIRBI and NBR are the best in the characterization of severity with a slight superiority of MIRBI,

- The severely burned forests have a West, North-Western, and South-Western exposure, which corresponds to the strong afternoon illumination,

- Severely burned forests are sometimes located in shallow slopes.

- Characterizing the severity provides alternative tools to prevent future forest fires in the function of the topography, vegetation, or environmental factors.

\section{ACKNOWLEDGMENT}

The authors would like to acknowledge the Faculty of Science and Technology of Beni Mellal for their logistical and financial support. We thank U.S. Geological Survey (USGS) 
and European Space Agency for providing the satellite images.

\section{REFERENCES}

[1] F. J. Lozano, S. Suárez-Seoane, M. Kelly, et E. Luis, « A multi-scale approach for modeling fire occurrence probability using satellite data and classification trees: A case study in a mountainous Mediterranean region », Remote Sens. Environ., vol. 112, n³ 3, p. 708-719, mars 2008.

[2] N. Koutsias et M. Karteris, « Burned area mapping using logistic regression modeling of a single post-fire Landsat-5 Thematic Mapper image », Int. J. Remote Sens., vol. 21, n 4, p. 673-687, janv. 2000.

[3] J. M. Sánchez, E. Rubio, F. R. López-Serrano, V. Caselles, et M. M. Bisquert, «Effects of fire on surface energy fluxes in a central Spain Mediterranean forest. Ground measurements and satellite monitoring », in Proceedings of the VII International EARSeL Workshop, 2009, p. 2-5.

[4] M. G. Turner, W. H. Romme, R. H. Gardner, et W. W. Hargrove, «Effects of fire size and pattern on early succession in yellowstone national park », Ecol. Monogr., vol. 67, n 4, p. 411-433, nov. 1997.

[5] L. B. Lentile* et al., «Remote sensing techniques to assess active fire characteristics and post-fire effects », Int. J. Wildland Fire, vol. 15, $\mathrm{n}^{\circ}$ 3, p. 319-345, sept. 2006

[6] «Wildfire effects on the soil seed bank of a maritime pine stand The importance of fire severity - ScienceDirect ». [En ligne]. Disponible

sur: https://www.sciencedirect.com/science/article/pii/S00167061120006 87. [Consulté le: 12-nov-2018].

[7] G. Bárcenas-Moreno, F. García-Orenes, J. Mataix-Solera, J. MataixBeneyto, et E. Bååth, «Soil microbial recolonisation after a fire in a Mediterranean forest », Biol. Fertil. Soils, vol. 47, n 3, p. 261-272, avr. 2011

[8] F. Maselli, S. Romanelli, L. Bottai, et G. Zipoli, « Use of NOAAAVHRR NDVI images for the estimation of dynamic fire risk in Mediterranean areas », Remote Sens. Environ., vol. 86, $\mathrm{n}^{\circ} 2$, p. 187-197, juill. 2003.

[9] F. Gonzalez-Alonso, J. M. Cuevas, J. L. Casanova, A. Calle, et P. Illera, «A forest fire risk assessment using NOAA AVHRR images in the Valencia area, eastern Spain », Int. J. Remote Sens., vol. 18, $\mathrm{n}^{\circ} 10$, p. 2201-2207, juill. 1997.

[10] F. J. Lozano, S. Suárez-Seoane, et E. de Luis, « Assessment of several spectral indices derived from multi-temporal Landsat data for fire occurrence probability modelling », Remote Sens. Environ., vol. 107, $\mathrm{n}^{\circ}$ 4, p. 533-544, avr. 2007.

[11] Chuvieco et al, « Remote sensing information for fire management and fire effects assessment », Journal of Geophysical Research: Biogeosciences, 2007.

[12] J. San-Miguel-Ayanz et al., « Forest fires in Europe, Middle East and North Africa $2016 », 2017$.

[13] B. Rabus, M. Eineder, A. Roth, et R. Bamler, « The shuttle radar topography mission - a new class of digital elevation models acquired by spaceborne radar», ISPRS J. Photogramm. Remote Sens., vol. 57 , $\mathrm{n}^{\circ} 4$, p. 241-262, févr. 2003.

[14] T. G. Farr et al., "The shuttle radar topography mission », Rev. Geophys., vol. 45, n 2, 2007.

[15] J. W. Rouse, « Monitoring vegetation systems in the Great Plains with ERTS », 1974.

[16] E. Chuvieco, M. P. Martin, et A. Palacios, « Assessment of differen spectral indices in the red-near-infrared spectral domain for burned land discrimination », Int. J. Remote Sens., vol. 23, n 23, p. 5103 5110, 2002.

[17] S. Trigg et S. Flasse, «An evaluation of different bi-spectral spaces for discriminating burned shrub-savannah », Int. J. Remote Sens., vol. 22, no 13 , p. 2641-2647, janv. 2001.

[18] C. H. Key et N. C. Benson, « Landscape assessment: remote sensing of severity, the normalised burn ratio and ground measure of severity, the composite burn index », FIREMON Fire Eff. Monit. Inventory Syst. Ogden Utah USDA For. Serv. Rocky Mt. Res Stn., 2005.

[19] G. P. Petropoulos, K. P. Vadrevu, G. Xanthopoulos, G. Karantounias, et M. Scholze, «A Comparison of Spectral Angle Mapper and Artificial Neural Network Classifiers Combined with Landsat TM Imagery Analysis for Obtaining Burnt Area Mapping », Sensors, vol. 10, $\mathrm{n}^{\circ} 3$, p. 1967-1985, mars 2010.

[20] A. Anggraeni et C. Lin, « Application of SAM and SVM Techniques to Burned Area Detection for Landsat TM Images in Forests of South Sumatra », in International Conference on Environmental Science and Technology, 2011, p. V2160-V2164.

[21] F. A. Kruse et al., « The spectral image processing system (SIPS) interactive visualisation and analysis of imaging spectrometer data », Remote Sens. Environ., vol. 44, n 2, p. 145-163, mai 1993.

[22] J. D. White, K. C. Ryan, C. C. Key, et S. W. Running, « Remote sensing of forest fire severity and vegetation recovery », Int. J. Wildland Fire, vol. 6, n 3, p. 125-136, 1996.

[23] J. M. C. Pereira, A. C. L. Sá, A. M. O. Sousa, J. M. N. Silva, T. N. Santos, et J. M. B. Carreiras, «Spectral characterisation and discrimination of burnt areas », in Remote Sensing of Large Wildfires. in the European Mediterranean Basin, E. Chuvieco, Éd. Berlin, Heidelberg: Springer Berlin Heidelberg, 1999, p. 123-138.

[24] Cindy Schmidt, "Introduction to Remote Sensing for Wildfire Applications ». 2015.

[25] C. Quintano, A. Fernández-Manso, et O. Fernández-Manso, « Combination of Landsat and Sentinel-2 MSI data for initial assessing of burn severity », Int. J. Appl. Earth Obs. Geoinformation, vol. 64, p. 221-225, févr. 2018

[26] M. C. Stambaugh, L. D. Hammer, et R. Godfrey, «Performance of Burn-Severity Metrics and Classification in Oak Woodlands and Grasslands », Remote Sens., vol. 7, nº 8, p. 10501-10522, août 2015.

[27] S. O. Sunderman et P. J. Weisberg, « Remote sensing approaches for reconstructing fire perimeters and burn severity mosaics in desert spring ecosystems », Remote Sens. Environ., vol. 115, $\mathrm{n}^{\circ}$ 9, p. 2384-2389, sept. 2011. 